\title{
P06
}

\section{Hydrodynamism Implication in Exploration:} Triassic Sandstones Reservoirs (Tagi Fm.)in Southern Tunisia

\author{
A. Maazaoui* (ETAP)
}


The main purpose of this technique was to help understand the complex flow patterns synthesis of Triassic sandstones reservoirs, main hydrocarbon producer in Southern Tunisia.

Compilation and mapping of chemical analysis of available formation water, static pressure, total dissolved solids with possible classification and potential level distribution at top TAGI formation was accomplished

The obtained results provide the basic information to understanding the relationship between recharge and discharge zones, origin and causes of variation in chemical composition and genetic water types of these subsurface waters.

Therefore for better assessment of possible and additional hydrocarbon accumulation It was essential to integrate the above results with facies distribution, tectonic events, fluids attributes and their hydrodynamic effects on entrapments and highlight the most likely trends of additional hydrocarbon accumulation (exploration leads).

This study can assist moreover to understand and to may explain why we have inefficiently drilled wells, by using fluids migration paths in respect to hydrocarbon draining area and perhaps to allow outlining the remaining prospective plays for accurate drilling.

In other hand, this method may increase the successful ratio of drilling if we have regular and sufficient chemical formation water analyses. 